Article

\title{
Identification and Characterization of the WOX Family Genes in Five Solanaceae Species Reveal Their Conserved Roles in Peptide Signaling
}

\author{
Xiaoxu Li ${ }^{\dagger}$, Madiha Hamyat ${ }^{\dagger}$, Cheng Liu, Salman Ahmad, Xiaoming Gao, Cun Guo, \\ Yuanying Wang * and Yongfeng Guo * iD \\ Key Laboratory for Tobacco Gene Resources, Tobacco Research Institute, \\ Chinese Academy of Agricultural Sciences, Qingdao 266101, China; liwei06@caas.cn (X.L.); \\ star_143_101@hotmail.com (M.H.); lc4115225111@163.com (C.L.); safitfa@yahoo.com (A.S.); \\ gaoxiaoming@caas.cn (X.G.); guocun_zzu@163.com (C.G.) \\ * Correspondence: wangyuanying@caas.cn (Y.W.); guoyongfeng@caas.cn (Y.G.) \\ + These authors contributed equally to this work.
}

Received: 21 April 2018; Accepted: 15 May 2018; Published: 17 May 2018

\begin{abstract}
Members of the plant-specific WOX (WUSCHEL-related homeobox) transcription factor family have been reported to play important roles in peptide signaling that regulates stem cell maintenance and cell fate specification in various developmental processes. Even though remarkable advances have been made in studying WOX genes in Arabidopsis, little is known about this family in Solanaceae species. A total of 45 WOX members from five Solanaceae species were identified, including eight members from Solanum tuberosum, eight from Nicotiana tomentosiformis, 10 from Solanum lycopersicum, 10 from Nicotiana sylvestris and nine from Nicotiana tabacum. The newly identified WOX members were classified into three clades and nine subgroups based on phylogenetic analysis using three different methods. The patterns of exon-intron structure and motif organization of the WOX proteins agreed with the phylogenetic results. Gene duplication events and ongoing evolution were revealed by additional branches on the phylogenetic tree and the presence of a partial WUS-box in some non-WUS clade members. Gene expression with or without CLE (clavata3 (clv3)/embryo surrounding region-related) peptide treatments revealed that tobacco WOX genes showed similar or distinct expression patterns compared with their Arabidopsis homologues, suggesting either functional conservation or divergence. Expression of Nicotiana tabacum WUSCHEL (NtabWUS) in the organizing center could rescue the wus-1 mutant phenotypes in Arabidopsis, implying conserved roles of the Solanaceae WOX proteins in peptide-mediated regulation of plant development.
\end{abstract}

Keywords: WOX family; Solanum lycopersicum; Solanum tuberosum; Nicotiana tabacum; Nicotiana tomentosiformis; Nicotiana sylvestris; WUS box

\section{Introduction}

The WUSCHEL-related homeobox (WOX) transcription factors belong to a plant-specific subgroup of the homeodomain (HD)-containing transcription factor superfamily, members of which possess a conserved DNA-binding homeodomain. A typical homeodomain of WOX transcription factors contains 60 amino acid residues with a helix-loop-helix-turn-helix structure [1]. Earlier expression studies and functional analyses indicated that WOX family members participate in various developmental processes of plants, including stem cell homeostasis and organ formation [1,2].

WOX transcription factors are broadly distributed in plant species, from ancient green algae to both monocots and dicots. In a recent study, 350 WOXs with a typical homeodomain were identified from 50 species in the plant kingdom. These members were grouped into three clades: WOXs from the 
ancient clade were identified in all species from algae to higher plants, the intermediate clade contained WOX proteins only from vascular plant species, and the modern clade or WUSCHEL (WUS) clade members were only identified in seed plants. The WOX family in the model eudicot plant Arabidopsis harbors 15 WOX members and 13 WOX transcription factors were identified on the genome of the model monocot plant rice [3].

A number of WOX genes have been reported to play a significant role in peptide signal-mediated stem cell homeostasis of different types of meristems [4]. The organizing center (OC) and the quiescent center $(\mathrm{QC})$ are essential to cell fate determination in the shoot and root apical meristem respectively. Arabidopsis thaliana WUSCHEL (AtWUS) which is specifically expressed in the OC has been shown to be the key transcription factor regulating stem cell homeostasis in the shoot apical meristem (SAM) [5]. WUS functions downstream of the CLAVATA (CLV) signaling pathway in which the CLV3 peptide signal is perceived by the CLV receptors including CLV1, CLV2, BAM1/BAM2 (barely any meristem 1 /barely any meristem 2), and receptor-like protein kinase 2 (RPK2) [6,7]. Type 2 C protein phosphatases POLTERGEIST and POLTERGEIST LIKE1 are signaling intermediates between CLV3 perception and WUS [8,9]. Transduction of the CLV signal leads to the restriction of WUS expression within the OC, while on the other hand WUS promotes expression of the peptide-encoding CLV3, forming a negative feedback loop, through which the population of stem cells within the SAM is maintained at a relatively constant level [10]. At the other end of a plant, AtWOX5 is specifically expressed within the QC in the root apical meristem (RAM) to define QC identity and regulate division and differentiation of RAM stem cells. Similar to WUS, WOX5 functions downstream of the signaling pathway initiated by another CLE peptide, CLE40 [11,12]. In fact, WOX5 can act interchangeably with WUS in the control of shoot and root stem cell niches $[13,14]$. Furthermore, AtWOX4 functions redundantly with AtWOX14 in defining the vascular stem cell niche together with the CLE peptide TDIF (tracheary element differentiation inhibitory factor) and its receptor TDIF receptor (TDR)/phloem intercalated with xylem (PXY) [15].

In addition, most of the other Arabidopsis WOX genes have also been shown to play regulatory roles in various cell fate determination processes including organogenesis and patterning. AtWOX2 and AtWOX 8 function together in regulating apical-basal axis formation during embryogenesis [16]. AtWOX 3 is expressed in the periphery of the shoot meristem and functions during lateral organ formation $[17,18]$. AtWOX6 is highly expressed in developing ovules and plays a central role in ovule patterning [19]. AtWOX7 is involved in lateral root formation [20]. AtWOX9 was found to functionally overlap with $A t W O X 8$ in promoting embryonic cell division and promoting growth of the vegetative SAM at later development stages [16,21,22]. AtWOX11 and AtWOX12 function redundantly in regulating the first-step cell fate transition during de novo root organogenesis of Arabidopsis leaf explants [23]. AtWOX13 was reported to be involved in replum development and fruit patterning [24].

Besides Arabidopsis, regulatory roles of WOX genes have been studied in a number of different plant species including rice, maize, sorghum, poplar, paper mulberry, grape, petunia, Pisum sativum L, Pyrus bretschneideri, Medicago truncatula and Nicotiana sylvestris [3,25-31]. Functions of WOX orthologues could be conserved or divergent among species [1]. However, only a limited number of WOX genes have been identified in the Solanaceae species so far and little is known about their functions [31].

In this study, we carried out a systematic study to identify and characterize the WOX gene family on the genomes of five Solanaceae species including tomato (Solanum lycopersicum), potato (Solanum tuberosum), common tobacco (Nicotiana tabacum), N. sylvestris and Nicotiana tomentosiformis. Among the Nicotiana species (collectively referred to as tobacco), common tobacco is an allotetraploid generated via natural crossing between $N$. sylvestris and $N$. tomentosiformis. We analyzed the expression patterns of WOX genes from N. tabacum and N. sylvestris and in comparison with their counterparts in Arabidopsis. Changes in expression of the N. tabacum WOXs after CLE peptide treatments were also determined to understand their potential roles in peptide signaling. Furthermore, we analyzed the function of NtabWUS in maintaining the shoot apical stem cell niche and in floral organ development. 


\section{Materials and Methods}

\subsection{Identification of WOX Members}

The latest versions of the genome annotations of S. lycopersicum (ITAG, Release 2.4), S. tuberosum (PGSC, Release 3.4), N. tabacum (K326), N. sylvestris and N. tomentosiformis were downloaded from SGN (Sol Genomics Network, http://solgenomics.net/). Previously reported AtWOX full-length and homeodomain amino acid sequences [3] were retrieved from The Arabidopsis Information Resource (TAIR: http: / / www.arabidopsis.org/), aligned with MAFFT v5.3 to produce Stockholm files and then subjected to HMMER v3.0 for building HMM (hidden Markov models) profiles. The HMM profiles were applied to perform HMM search against the annotated Solanaceae protein databases with an E-value cutoff of 1.0. Furthermore, using both the full-length and homeodomain amino acid sequences of AtWOXs, BLASTP search was performed to identify additional potential WOX proteins with an E-value cutoff of 0.01 . The protein sequences obtained from the two above-described approaches were combined and redundant entries were removed manually. The resulted hit sequences were then analyzed with both Pfam (https://pfam.xfam.org/) and SMART (http://smart.embl.de/) to ensure the presence of the homeobox domain.

\subsection{Multiple Sequence Alignment and Phylogenetic Analysis}

Multiple sequence alignment of both full-length and homeodomain amino acid sequences of AtWOXs and putative WOX members from the Solanaceae species was performed using MAFFT v5.3 under the default settings with manual editing. Phylogenetic trees were constructed using three different approaches based on the alignment results. A neighbor-joining (NJ) tree was constructed from the alignment of full-length amino acid sequences of AtWOXs and Solanaceae WOX members using MEGA package 6.06 with the following parameters: Poisson correction, pairwise deletion and bootstrap values (1000 replicates). A maximum likelihood (ML) tree was generated from the alignment of homeodomain amino acid sequences of AtWOXs and Solanaceae WOX members with the PhyML software package 3.0 using 100 replicates and the JTT model with gamma-distribution of rates (JTT+G model) advised by ProtTest 2.4. A Bayesian inference (BI) tree was constructed from the alignment of homeodomain amino acid sequences of AtWOXs and Solanaceae WOXs. The same JTT+G model was selected with the assistance of ProtTest 2.4. For the BI tree, the analysis was performed with MrBayes (http:/ / mrbayes.sourceforge.net/) for 2,500,000 generations with trees sampled every 1000 generations and a burn-in of 625. Theses tree files were visualized with FigTree 1.4.0.

\subsection{Gene Structure and Motif Analysis}

Exon-intron structures were analyzed and illustrated with the Gene Structure Display Server (GSDS: http:/ / gsds.cbi.pku.edu.cn/) [32] using both coding sequences (CDS) and genomic sequences obtained from the Sol Genomics Network. The conserved motifs in AtWOXs and Solanaceae WOX proteins were identified with the assistance of MEME 4.9.1 (Multiple Expectation Maximization for Motif Elicitation, http:/ / meme-suite.org/), and visualized by WebLogo [33] (http:/ / weblogo.berkeley. edu/logo.cgi). Parameters were set as follows: distribution of motif occurrences, zero or one per sequence; maximum number of motifs, 8; optimum motif width, $\geq 6$ and $\leq 100$; and the optimum number of sites for each motif, $\geq 2$ and $\leq 200$.

\subsection{Tobacco Materials and Growth Conditions}

Nicotiana sylvestris and N. tabacum (cultivar K326) seeds were sowed in soil pots covered with plastic film. Plants were grown in a growth room at $25{ }^{\circ} \mathrm{C}$ under continuous light. Seven-week-old (8 leaf stage) plants of $N$. sylvestris and $N$. tabacum were used for gene expression analysis. Five different tissue types including root, root tip, stem, shoot tip, and leaf were used for RNA extraction. Tissues were harvested, put in liquid nitrogen immediately and stored at $-80^{\circ} \mathrm{C}$ before RNA extraction. 


\subsection{Synthetic Peptide Application on Tobacco Seedlings}

Nicotiana tabacum seedlings were grown on Murashige and Skoog (MS) media containing $10 \mu \mathrm{M}$ synthetic CLV3 peptides (CLV3p: RTVPSGPDPLHH) for 21 days. Plates were incubated at $25^{\circ} \mathrm{C}$ with $16 \mathrm{~h}$ light and $8 \mathrm{~h}$ dark per day. The CLV3p were ordered from Genscript Biotechnology (Beijing, China).

\subsection{RNA Extraction and quantitative real time-PCR}

Total RNA was extracted with TRIzol (Ambion, Thermo Fisher Scientific, Waltham, MA, USA) according to the manufacturer's instructions and treated with DNase I (Thermo Fisher Scientific) to remove DNA contamination. First-strand cDNA synthesis was performed using an M-MLV (Moloney murine leukemia virus) Reverse-Transcription Kit (Invitrogen, Carlsbad, CA, USA). The cDNA was diluted 1:30 with $\mathrm{ddH}_{2} \mathrm{O}$ and used as templates for quantitative real time PCR (qRT-PCR). The FastStart Universal SYBR Green Master (ROX, Roche, Basel, Switzerland) was used to detect gene expression. The qRT-PCR was performed on a 7500 Real-Time PCR System (Applied Biosystems, Waltham, MA, USA) and PCR reactions were performed in a total volume of $20 \mu \mathrm{L}$ containing $1 \mu \mathrm{M}$ of each primer $(0.6 \mu \mathrm{L}), 50 \mathrm{ng} / \mu \mathrm{L} \mathrm{cDNA}(2 \mu \mathrm{L})$, and $2 \times$ FastStart Universal SYBR Green Master $(10 \mu \mathrm{L})$. Gene-specific primers were designed using Primer 5 . The $N$. tabacum and N. sylvestris beta-actin genes were used as internal controls. Relative gene expression levels were calculated using the $2^{-\Delta \Delta C T}$ method. Primers used are listed in Supplementary Table S1.

\subsection{Expression Analysis of AtWOXs, NsylWOXs and NtabWOXs}

Expression data of AtWOXs were obtained from the database TraVA (travadb.org). Together with qRT-PCR data of NsylWOXs and NtabWOXs, all expression data were normalized and visualized with $\mathrm{R}$ [34].

\subsection{Subcellular Localization}

The coding region of NtabWUS excluding the terminator codon was amplified and ligated into the $p E a s y$-Blunt vector, and then the NtabWUS and green fluorescent protein (GFP) fragments were cloned into the $p C H F 3$ vector by Infusion (Invitrogen) separately, generating the NtabWUS-GFP fusion construction driven by the CaMV35S promoter. The recombinant construct and control were used for Agrobacterium-mediated transient expression in Nicotiana benthamiana [35]. Fluorescence signals were captured using a Confocal Microscope (TCS-SP8 Leica, Wetzlar, Germany) four days after infiltration. DNA dye 4,6-diamidino-2-phenylindole (DAPI) staining was used to show the position of the nucleus.

\subsection{Transactivation Activity Assay}

The coding sequence of NtabWUS was inserted into the EcoRI restriction sites of the pBridge vector with Infusion (Clontech, Palo Alto, CA, USA). This construct and control $p$ Bridge vector were transformed into yeast strain AH109 (Clontech). Yeast transformation were performed following to the manufacturer's instructions (Clontech). The transformed yeast cells were incubated on synthetic dextrose (SD) medium lacking tryptophan (SD/ - Trp) and SD medium lacking tryptophan supplemented with X-Gal (SD/-Trp-x-gal) plates at $30^{\circ} \mathrm{C}$ for four days. The transactivation activity was evaluated based on $\beta$-galactosidase activity.

\subsection{Genetic Complementation Analysis}

The Arabidopsis wus-1 mutant (NASC ID: CS15) and marker line J2341 (NASC ID: CS9118) were ordered from NASC (http://arabidopsis.info/). As a typical ethyl methanesulfonate induced mutant, wus-1 changed the second exon-intron border ( $G$ to $A$ ) and resulted in a predicted translational stop a few codons later. A specific primer pair (F: GGATTTGGGTTAGTAGAAAA/R: ATCGAAGAAGTTGTAAGGTG) was designed to amplify a fragment residing this SNP and then sent for sequencing. If the mutant was heterozygous (wus-1+/-), PCR with this primer pair would 
give a double peak with ' $\mathrm{G} / \mathrm{A}^{\prime}$, and when wus-1 was homozygous it would show a single peak of ' $\mathrm{A}$ '. The wus-1 mutant was crossed with J2341 and presence of the GAL4-GFP enhancer trap reporter J2341 in the $\mathrm{F}_{1}$ plants was PCR confirmed. To generate the construct for complementation analysis, the coding sequence of NtabWUS was cloned into the $p P Z P 211$ vector together with the AtWUS promoter. The resulted construct was used to transform wus-1+/- J2341 plants via the floral dip method and transformants were selected on 1/2 MS medium plates containing $50 \mathrm{mg} / \mathrm{mL}$ of Kanamycin. The Confocal Microscopy (Leica, TCS-SP8) was performed to test the GFP fluorescence and $488 \mathrm{~nm}$ laser lines were used for excitation of GFP [14].

\section{Results}

\subsection{Identification of WOX Transcriptional Factors}

To identify WOX family genes in the Solanaceae species, homeodomain sequences of 15 previously identified AtWOX proteins were employed to build the HMM profile which was then used as queries to perform HMM searches against related protein databases. Furthermore, BLASTP searches were carried out to obtain more potential WOX proteins using both full-length sequences and homeodomain sequences of known AtWOX proteins as queries. Redundant sequences were removed through manual reconstruction. To further verify the reliability of these candidate sequences, Pfam and SMART analyses were carried out to ensure the presence of the homeodomain in each candidate protein.

A total of 45 WOX proteins were identified, including eight from $N$. tomentosiformis, eight from S. tuberosum, ten from N. sylvestris, ten from S. lycopersicum, and nine from N. tabacum (Supplementary Dataset S1). Considering that $N$. tabacum is an allotetraploid which was generated via natural crossing between $N$. sylvestris and $N$. tomentosiformis, the smaller size of the $N$. tabacum WOX family could be due to low sequence conservation and/or incomplete genome information of N. tabacum. More WOX members might be identified in the N. tabacum genome in future.

To better understand the orthologous relationships between AtWOXs and the newly identified Solanaceae WOX members, an unrooted phylogenetic tree constructed with full-length sequences of AtWOX proteins (Supplementary Dataset S2) was employed to identify potential orthologues. Based on NJ phylogenetic analysis, homologues of AtWOXs from the Solanaceae species were given names with prefixes indicating species name ( $\mathrm{Sl}$, S. lycopersicum; St, S. tuberosum; Ntab, N. tabacum; Ntom, N. tomentosiformis; Nsyl, N. sylvestris) and suffix indicating subgroups of the WOX family (WOX1, WOX2 etc.). Furthermore, letters $a, b, c$ or $d$ were added to the end of the names based on phylogenetic relationships to distinguish paralogues.

\subsection{Multiple Sequence Alignment}

To examine features of the homeodomain sequence within the WOX proteins, multiple sequence alignment was carried out with MAFFT using homeodomain sequences of the 60 WOX proteins, including the 45 Solanaceae WOXs identified in this study and the 15 Arabidopsis WOX family members. The alignment results showed that the homeodomain exhibited a high-level conservation among the six plant species (Figure 1). The typical size of the homeodomain was found to be 60 amino acids with a helix-loop-helix-turn-helix structure. It has been reported that the homeodomain harbors 11 conserved amino acid residues including $\mathrm{Q}, \mathrm{L}$ and $\mathrm{Y}$ in helix 1, I, V, W, F, N, K, R and R in helix 3 [36]. Six more residues were identified to be conserved among homeodomain sequences from rice, sorghum, maize, Arabidopsis and poplar, including P, I and L in helix 2, F and Q in helix 3 and G in the turn [3]. Not surprisingly, it was found that all the above mentioned 17 amino acid residues are highly conserved among the 60 homeodomain sequences in this study. In addition, three highly conserved residues were identified from homeodomain sequences of the Solanaceae WOXs, including E in helix 1, I in helix 2 and $\mathrm{N}$ in helix 3. 


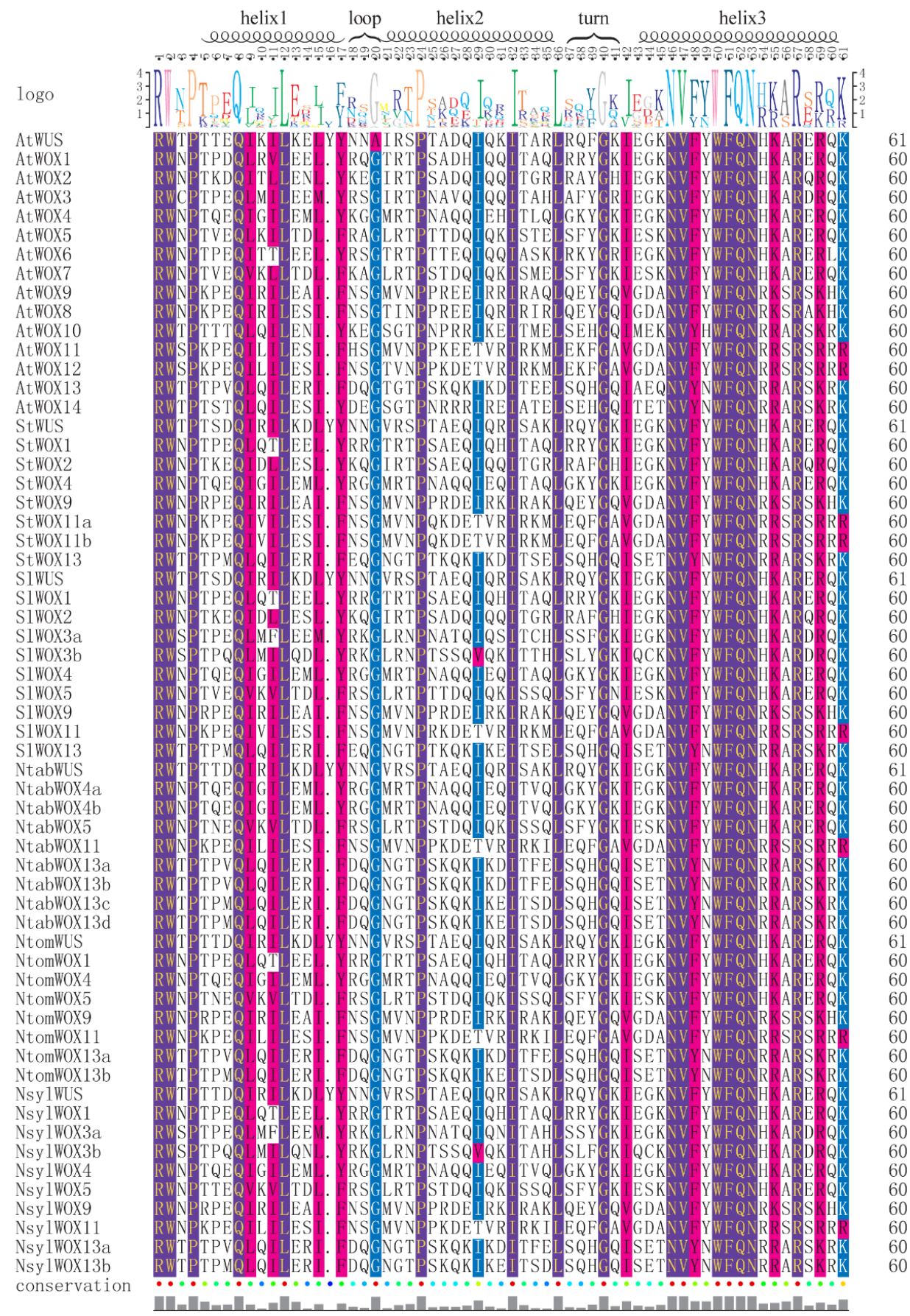

Figure 1. Homeodomain domain sequence analysis of WOX (WUSCHEL-related homeobox) family members. The homeodomain of the newly identified WOX family members contains the typical helix-loop-helix-turn-helix structure. The completely conserved residues are purple colored and highly conserved residues are red or blue colored, all visualized by Texshade (https://ctan.org/pkg/texshade).

\subsection{Phylogenetic Analysis}

To investigate the phylogenetic relationship between WOX members of the six dicotyledonous species and to group them into subfamilies, we performed phylogenetic analysis based on the multiple sequence alignment of full-length or homeodomain sequences of the 60 WOX proteins. To gain more confidence on the reliability of our results, three different methods of tree construction were used, 
including NJ (Figure 2), ML (Figure 3) and BI (Figure 4). We found good support values with similar topologies for all three trees. In consistent with previous studies [25,37], WOX members fell into three well-organized clades with 33, 14 and 13 members in the modern clade, the intermediate clade and the ancient clade, respectively.

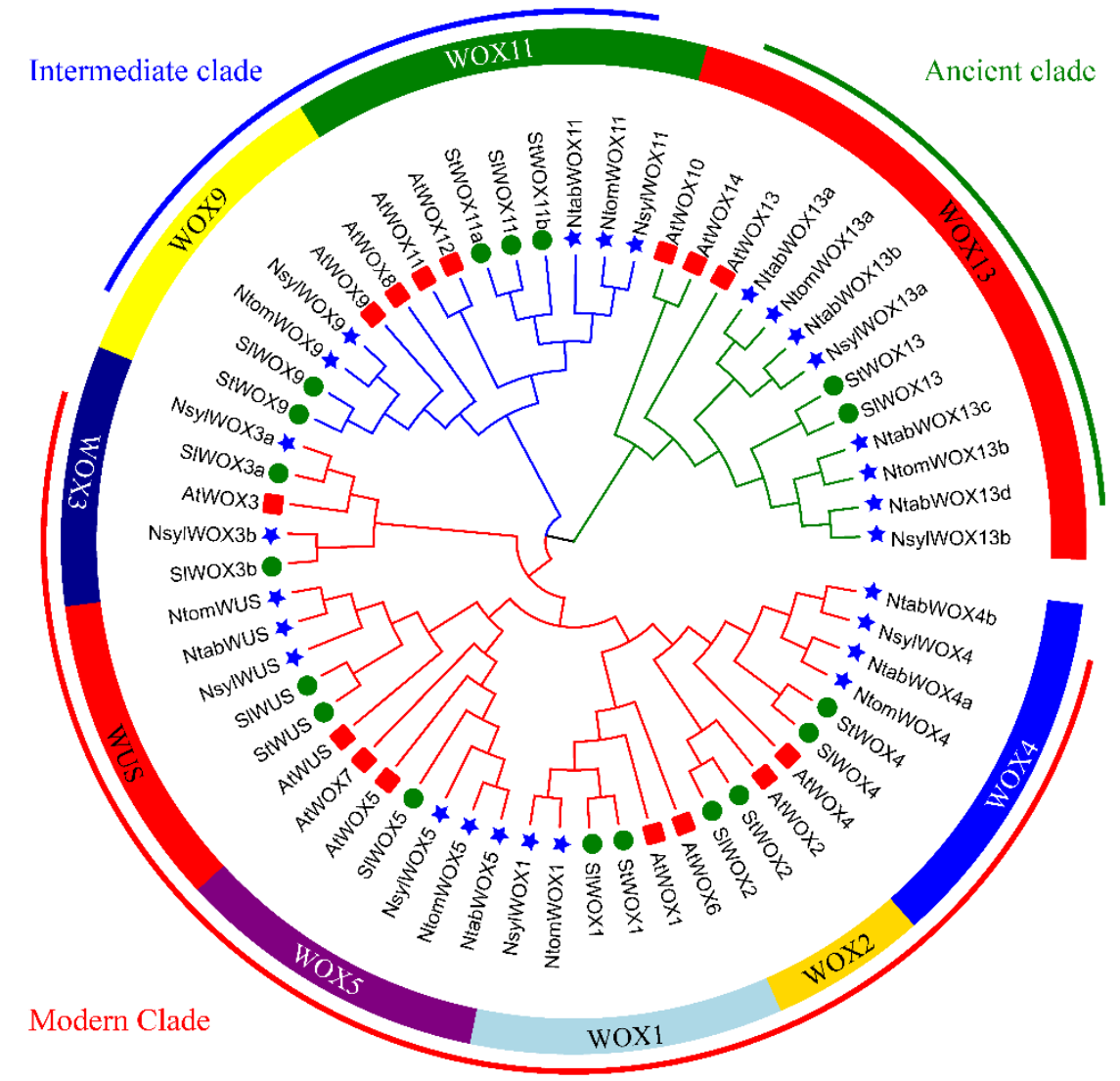

Figure 2. Phylogenetic analysis of WOX family proteins. The phylogenetic tree was generated from the alignment of 60 WOX proteins with 1000 bootstrap replicates. The WOX proteins were classified into three clades and nine subgroups based on phylogenetic analysis using the neighbor-joining (NJ) method. Red squares indicate Arabidopsis WOX genes, green circles indicate potato and tomato WOX genes, and blue stars indicate tobacco WOX genes.

To get further insight into the evolution process, the 60 WOX proteins were sub-divided into 9 subgroups (Figure 2). The ancient clade contains the WOX13 subgroup with 13 WOX members, harboring AtWOX13, AtWOX10, and AtWOX14. The intermediate clade which contains 14 WOXs homologous to AtWOX8, AtWOX9, AtWOX11 and AtWOX12, was further divided into two subgroups, the WOX9 subgroup and the WOX11/12 subgroup. The modern clade (or the WUS clade) contains 33 WOXs that are homologous to AtWOX1-7 and AtWUS. The members in the modern clade were further divided into 6 subgroups, namely the WOX1, WOX2, WOX3, WOX4, WOX5/7 subgroups and the WUS subgroup.

WOX proteins in each of the three major clades were identified from all the five Solanaceae species, confirming that the divergence of the WOX gene family occurred before the divergence of the six plant species in this study. However, no homologue of AtWOX6-8, AtWOX10 and AtWOX14 was identified in the Solanaceae species, suggesting possible gene duplication of Arabidopsis WOX family members. The notion of gene duplication in Arabidopsis is also supported by the fact that two pairs of highly homologous WOX proteins (AtWOX11/12 and AtWOX10/14) that share a node on the phylogenetic tree were identified in Arabidopsis while no such homologue pair was found in the Solanaceae species 
(Figure 2). As expected, WOX families of the five Solanaceae species were found more closely related to each other than to that of Arabidopsis. All the close interspecies orthologous pairs that share a node on the phylogenetic tree were pairs between the Nicotiana species or between tomato and potato.

The WUS subgroup contained a complete set of orthologous sequences from all the six plant species, implying conserved and specified functions of the WUS subgroup members. No homologue of the WOX2 subgroup was identified in the Nicotiana species. No WOX3 subgroup member was identified from potato, N. tomentosiformis or N. tabacum, implying possible deletion events during evolution. In the WOX4 and WOX13 subgroups, the number of NtabWOXs is twice as many as that of NsylWOXs and NtomWOXs. It is likely that in subgroups WOX4 and WOX13, the allotetraploid N. tabacum gained equal number of genes from each of its diploid ancestors.

\subsection{Exon-Intron Organization}

Exon-intron organization could provide useful information about the evolution of a gene family. WOX members within the same subgroup were found to have similar exon/intron structures except that genes in the WOX9 subgroup showed complex exon-intron structures and significant variation in the numbers of introns (Figure 3).
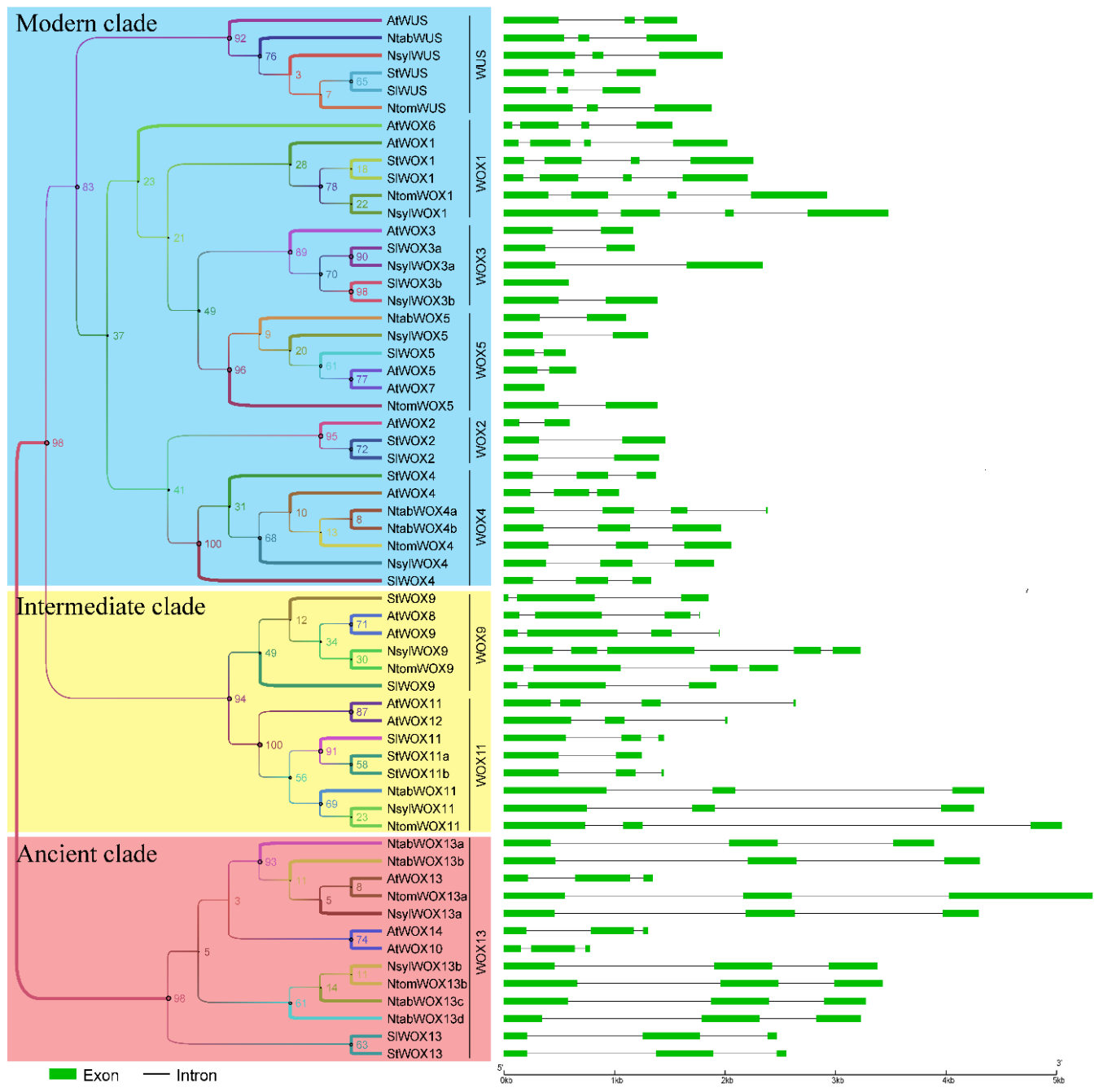

Figure 3. Maximum-likelihood (ML) tree and gene structures of WOXs in Arabidopsis, tomato, potato and tobacco. The phylogenetic tree summarizes the relationships within the 60 members of the WOX family. The tree was constructed by PhyML. Exons and introns are represented by green boxes and grey lines, respectively. 
A number of WOX genes have exon/intron structures distinct from other members of the same subgroup. For example, NtabWOX4a has four exons whereas all the other members of the WOX4 subgroup contain three exons. SIWOX3b and AtWOX7 have a single exon while other members of their subgroups all have two exons. Slight variation in exon/intron length was also observed. NtomWOX11 contains the longest intron of more than $3 \mathrm{~kb}$ and NtomWOX13a has an exon of more than $1 \mathrm{~kb}$. Such divergence in number or length of exon/intron might be the result of gain or loss of DNA fragments, chromosome rearrangement or fusion, which could ultimately lead to generation of functionally distinct paralogues. Genes in the more conserved ancient clade all have similar exon/intron structures while the modern clade shows the most variation.

\subsection{Protein Domain Analysis}

In addition to the homeodomain, which is present in all the WOX members, seven more conserved motifs were identified using the MEME online tool. The motifs were named Motif 1-8 with Motif 1 being the homeodomain. Supporting the results of the phylogenetic analysis, one or two motifs were found to be shared by WOX proteins within the same clade in addition to the homeodomain: Motif 7 (the WUS box) is conserved in the modern clade, Motif 6 and 4 are present in all the intermediate clade members but not in the other two clades, and Motif 2 is unique to the WOX members of the ancient clade (Figure 4; Supplementary Dataset S3).

A number of protein motifs were identified in this study which might be specific to the Solanaceae family or related species. This includes Motif 5 in the WOX 4 subgroup and Motif 8 in the WUS subgroup that are present in all the Solanaceae WOX proteins but not in AtWOXs. Similarly, Motif 3 is only present in some of the Solanaceae WOXs in the ancient clade (Figure 4).

It has been reported that three functional domains of AtWUS, including the acidic region, the WUS box and the EAR-like motif, contribute significantly to its function as a transcription factor [2,38,39]. Among these functional domains, the WUS box domain is only present in members of the modern clade. In this study, a WUS box was identified in 32 of the 33 modern clade WOX members (Figure 5A). Interestingly, a partial WUS box was identified in the WOX11 subgroup members of the intermediate clade in the Nicotiana species. The partial WUS box contains a TN-LFP motif instead of the TL-LFP motif as in the WUS box (Figure 5B). The conservation of this partial WUS box in the Nicotiana species might be related to certain functions of these WOX genes and this might be an indication of ongoing evolution of the WUS box. Furthermore, the EAR-like domain was found to be present in all members of the WUS and WOX5 subgroups except AtWOX7 (Figure 5C). Note that AtWOX7 also lacks the WUS box and is the only WOX protein in this study that contains no other conserved motif except the homeodomain. The functional acidic region of AtWUS which is localized at the N-terminal side of the WUS box was found not strictly conserved among the WUS members from the Solanaceae species, although all of these proteins contain a (Q/E) Q/E]EEE motif (Figure 5D). According to a previous report [3], the acidic region was not detected in rice and maize, indicating that this functional domain is perhaps only present in WUS subgroup members of certain plants. Interestingly, amino acid $Y$ in helix 1 of the homeodomain was found to be conserved among all the WUS subgroup members (Figure 1). 


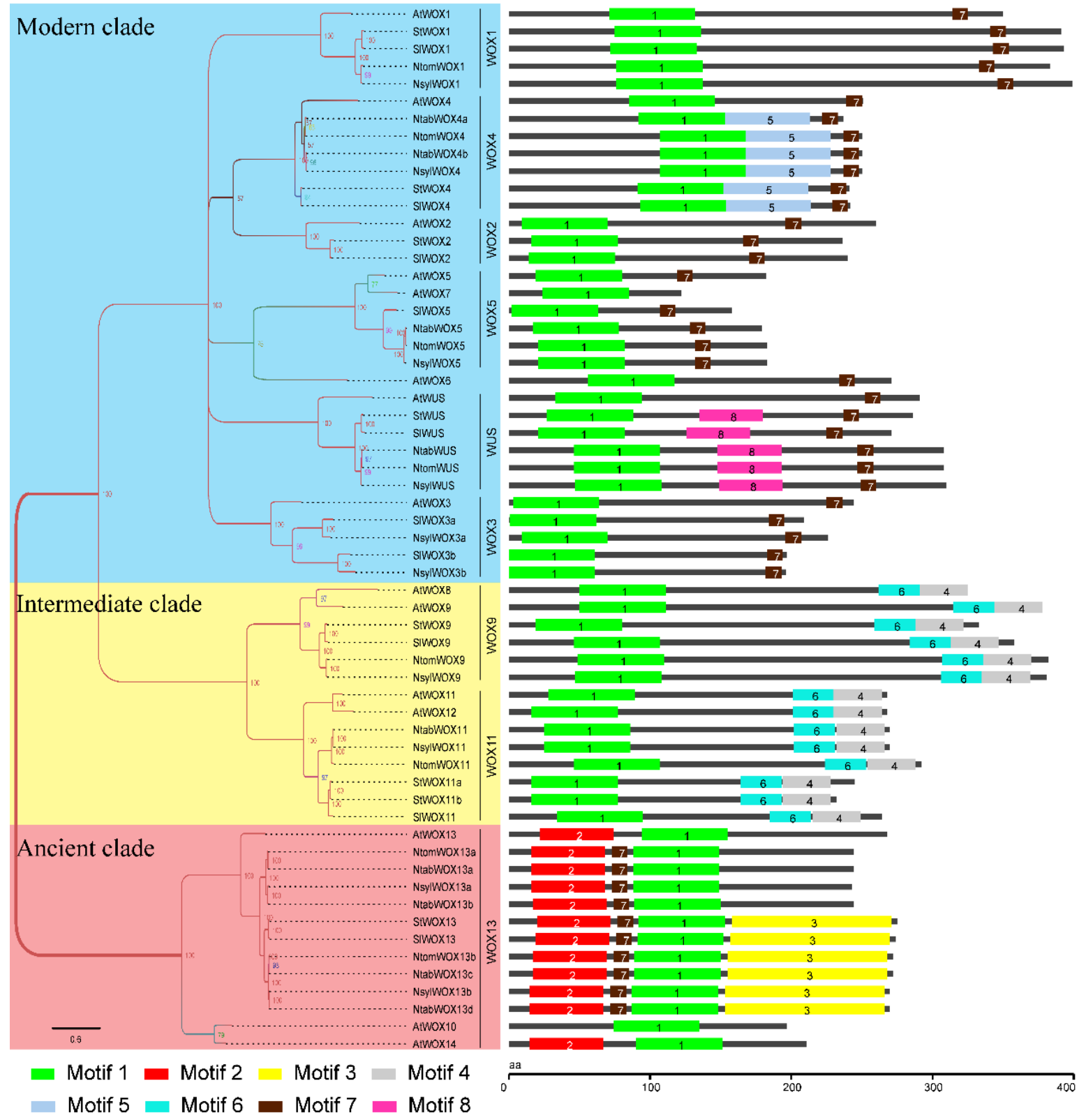

Figure 4. Bayesian inference (BI) tree and motif analysis. The phylogenetic tree revealed the relationships among the 60 members of the WOX protein family, which was generated by MrBayes. The conserved motifs identified by MEME v4.9.1 (http://meme-suite.org/) are highlighted with colored boxes. 
A

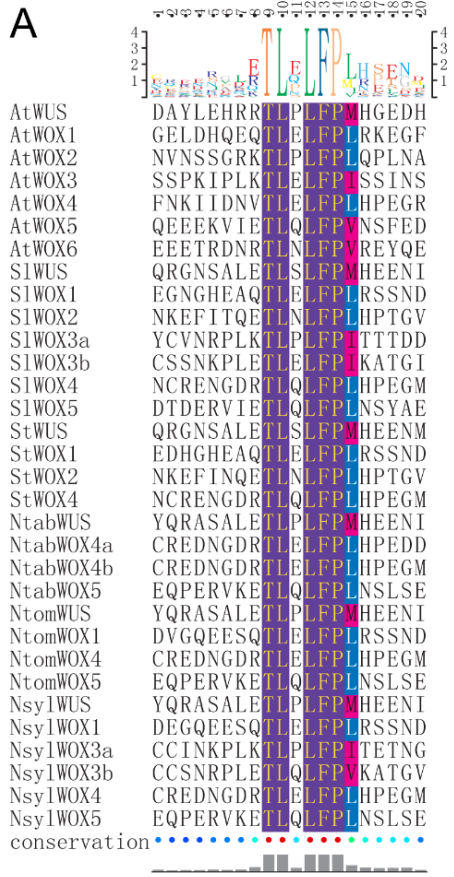

B

AtWOX8

AtWOX9

AtWOX10

AtWOX14

NtabWOX11

NtomWOX11

Nsy1W0X11

conservation

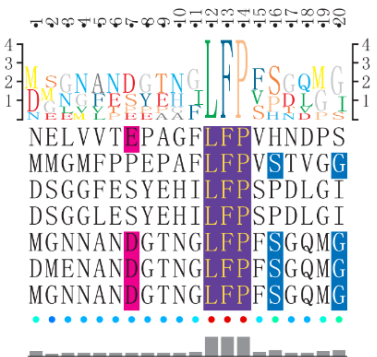

C

AtWUS

S1WUS

StWUS

NtabWUS

NtomWUS

Nsy1WUS

AtWOX5

S1W0X5

NtabW0X5

NtomW0X5

Nsy1W0X5

conservation

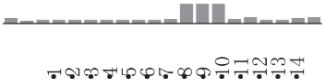

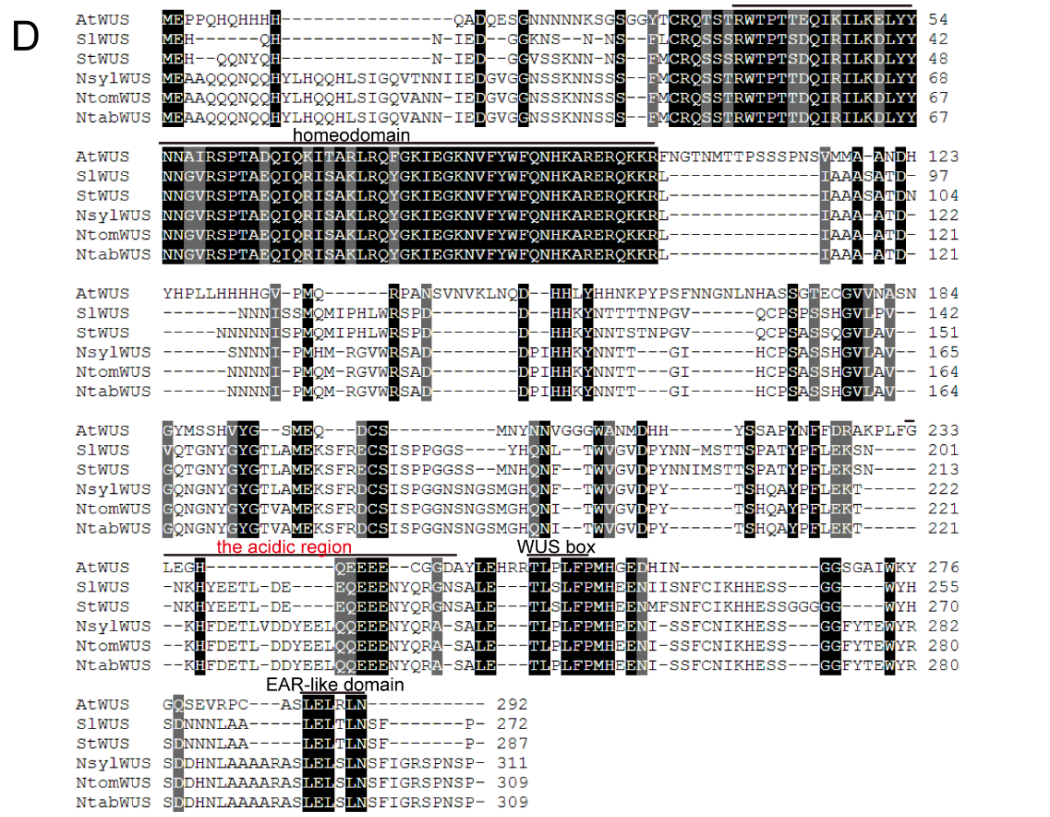

Figure 5. Functional domain analysis of WOX transcription factors in Arabidopsis, tomato, potato and tobacco. (A) Alignment of the WUS box. 32 WOXs were found to contain the WUS box and all of them belong to the modern clade. The completely conserved residues are purple colored and highly conserved residues are red or blue colored, all visualized by Texshade. (B) Alignment of the partial WUS box. The partial WUS box was observed in the WOX11 subgroup of the three tobacco species, containing a TN-LFP motif. The completely conserved residues are purple colored and highly conserved residues are red or blue colored, all visualized by Texshade. (C) Alignment of the EAR-like motif. All the identified WOX members in the subgroups WUS and WOX5 contain this functional domain. Conserved residues are shown below the alignment. The completely conserved residues are purple colored and highly conserved residues are red or blue colored, all visualized by Texshade. (D) Alignment of the acidic region. SIWUS, StWUS, NtabWUS, NsylWUS and NtomWUS were aligned by MAFFT. The completely conserved residues are black box shaded and highly conserved residues are grey box shaded. 


\subsection{Expression of WOX Genes in Different Tissues}

In order to get some idea of where the WOX genes function in the plant, we analyzed the expression patterns of WOX members from Arabidopsis, N. tabacum and N. sylvestris in different tissue types including root, root tip, stem, shoot tip and leaf at the early developmental stage. Transcript levels of N. tabacum and N. sylvestris were retrieved from qRT-PCR data. Expression data for AtWOXs were collected from the AtGenExpress Visualization Tool. The WOX genes were found to be expressed broadly in different tissues with considerable variations between clades, subgroups, and individual genes (Figure 6).
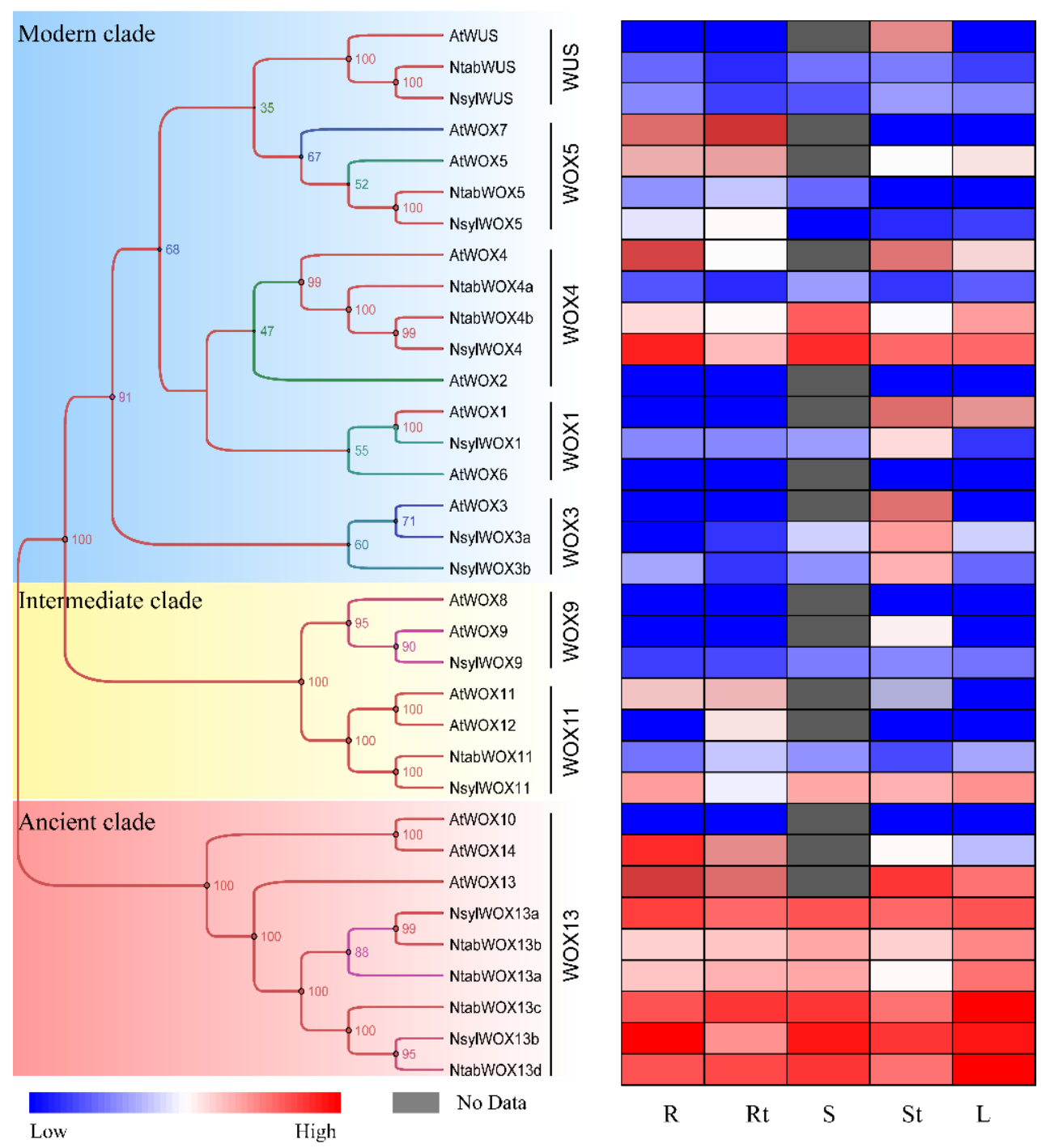

Figure 6. Expression patterns of the WOX gene family members in Arabidopsis, Nicotiana tabacum and Nicotiana sylvestris. The phylogenetic tree was generated by MAGE v.6.06 with 34 WOX members from Arabidopsis, N. tabacum and N. sylvestris. The expression pattern data were normalized and visualized by R. R, root, Rt, root tip, S, stem, St, shoot tip, L, leaf.

Genes in the same subgroup tended to have similar patterns of expression (Figure 6). Members of the ancient clade, homologues of AtWOX13 from N. tabacum and N. sylvestris, including NsylWOX13a, NsylWOX13b, and NtabWOX13a-d, showed a similar expression pattern with relatively high expression levels in most of the five tested tissues. Members of the WUS subgroup exhibited higher expression in shoot tips than in the other tissues, implying that these WOX genes might be involved in regulation of 
shoot apex development like AtWUS. In contrast, members in the WOX5 subgroup were found to be abundantly expressed in roots and root tips, indicating a possible role of NslyWOX5 and NtabWOX5 in root development. Consistent with the role of WOX1 homologues in leaf blade outgrowth and vascular patterning [31,40], NsylWOX1 showed increased expression at shoot tips and in leaves. AtWOX3 showed functional redundancy with AtWOX1 at early stages of leaf development in Arabidopsis [41]. It is not surprising that NsylWOX3a and NsylWOX3b showed a similar expression pattern with NsylWOX1. NtabWOX11 was found to be highly expressed in root tips, suggesting that this gene might have a similar role in root development as its Arabidopsis orthologue AtWOX11 [42].

\subsection{Expression Changes of Tobacco WOXs upon CLE Peptide Treatments}

To understand potential functions of the WOX members in CLE peptide signaling, we treated tobacco plants with synthesized CLV3p and changes in expression of the nine N. tabacum WOXs after peptide treatments were determined. As expected, treatments with $10 \mu \mathrm{M}$ CLV3p dramatically inhibited the tobacco root growth of tobacco (Figure 7). Three-week-old seedlings were harvested and real-time qPCR was performed with RNA samples extracted from roots, root tips, shoots, shoot tips and leaves. The expression of NtabWOX5 in root and root tip was significantly lower in the CLV3p treated seedlings. Similarly, NtabWUS expression in shoot and shoot tips was significantly inhibited by CLV3p treatments (Figure 8). In contrast, expression of NtabWOX4a, NtabWOX4b and NtabWOX11 was strongly induced by CLV3p treatments. Interestingly, expression of WOX13a, WOX13b, WOX13c and WOX13d was promoted in the root, leaf, shoot and shoot tip while significantly inhibited in root tip by CLV3p treatments (Figure 8). Overall, NtabWOXs showed transcriptional responses to CLV3p treatments, suggesting their potential roles in various developmental processes mediated by CLE peptide signaling.

A

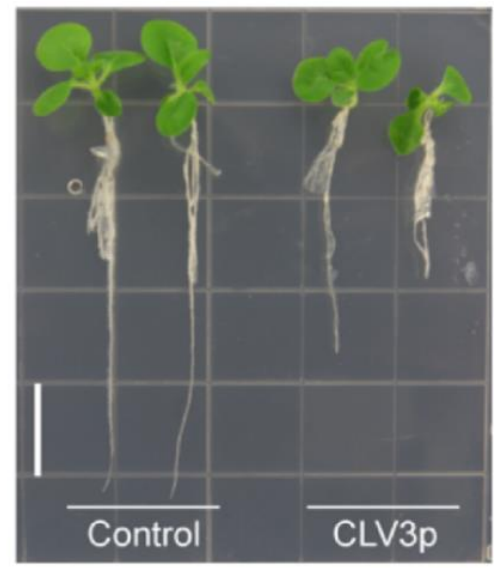

B

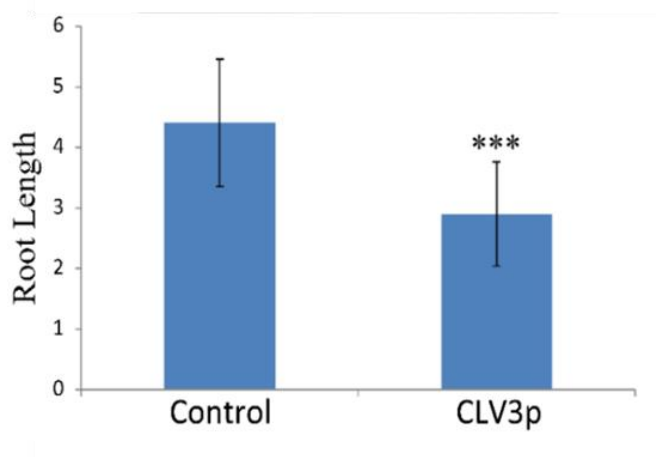

Figure 7. The phenotypes of common tobacco seedlings upon treatments of CLV3p peptides. The peptide treatment experiment was independently repeated for three times, each consisting five individual plants from control as well from CLV3p treated plants. The error bars indicated standard deviation (SD), and asterisks indicated the significant difference compared with the control group (*** $p<0.001$ ), calculated by performing $t$-test with GraphPad Prism 5. (A) The phenotypes of tobacco growth inhibition upon application of CLV3p. (B) Effect of $10 \mu \mathrm{M}$ CLV3p on root length of tobacco. 

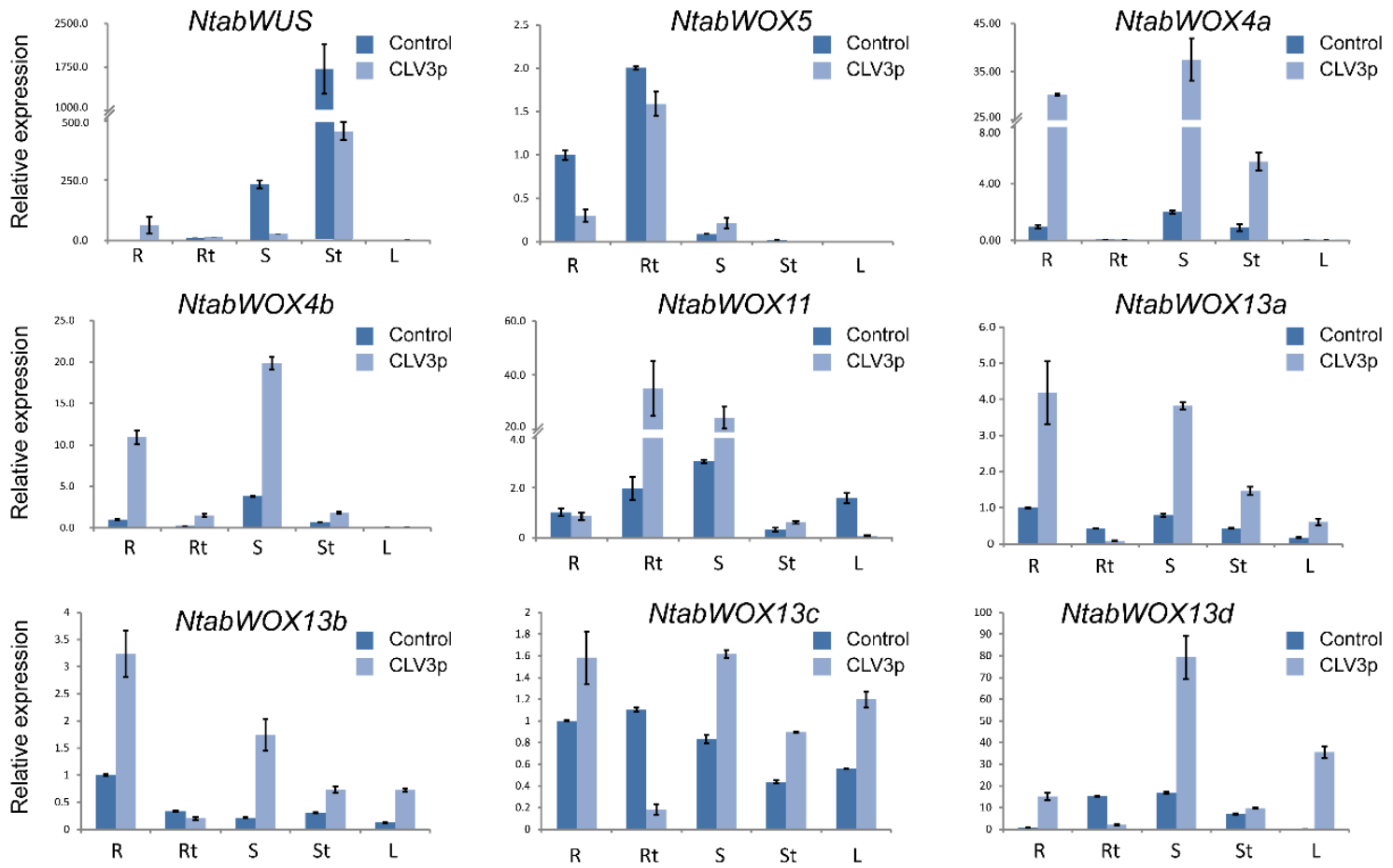

Figure 8. CLV3p-induced changes in transcript levels of NtabWOXs. Quantitative real-time PCR was used to detect NtabWOXs expression levels treated with CLV3p. These qPCR data presented were obtained from three independent biological replicates with three technical repeats. The error bars indicated SD. R, root, Rt, root tip, S, stem, St, shoot tip, L, leaf.

\subsection{Subcellular Localization and Transactivation Activity Assay}

To explore potential roles of the newly identified WOX members as transcription factors, the subcellular localization of NtabWUS was investigated. The ORF of NtabWUS excluding the stop codon was cloned to be in frame with a GFP reporter gene, which was under the control of the CaMV-35S promoter. The fluorescence of the fusion protein was specifically localized in the nucleus as being verified by DAPI staining, whereas the control signal of 35S:GFP was distributed throughout the cell (Figure 9A).

In this study, the transactivation activity assay was used to investigate whether NtabWUS has transactivation activity and functions as a transcription factor in regulating the expression of downstream target genes. The coding region of NtabWUS was fused with the GAL4 DNA binding domain (GAL4 BD) in pBridge and transformed into yeast strain AH109, which is an engineered strain with UAS fused with reporter genes. The transactivation activity was evaluated based on reporter gene activity. The yeasts were selected on SD medium lacking tryptophan (SD/-Trp). Then, the yeast transformants with the $p B D-N t a b W U S$ construct turned blue in the presence of $\mathrm{X}-\beta-\mathrm{Gal}$, whereas the negative control did not (Figure 9B), indicating transactivation activity. Taken together, these results indicate that NtabWUS may function as a transcriptional activator. 
A
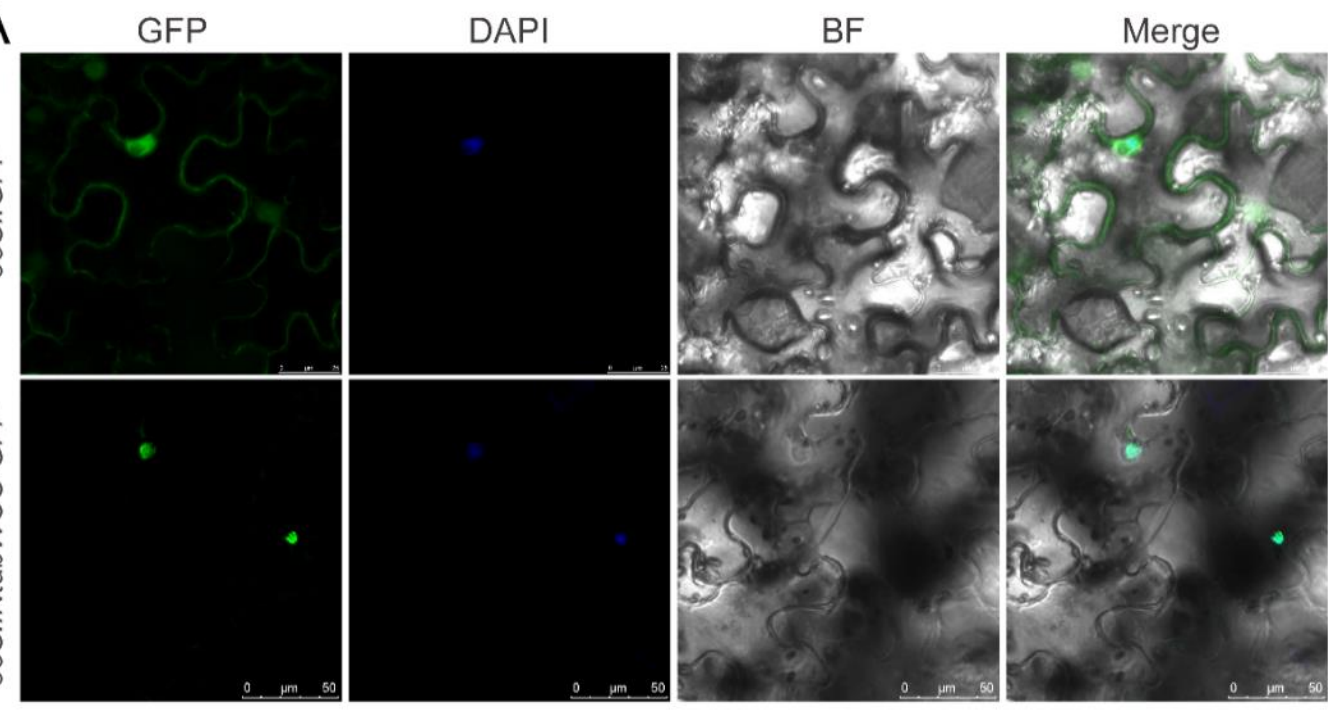

B
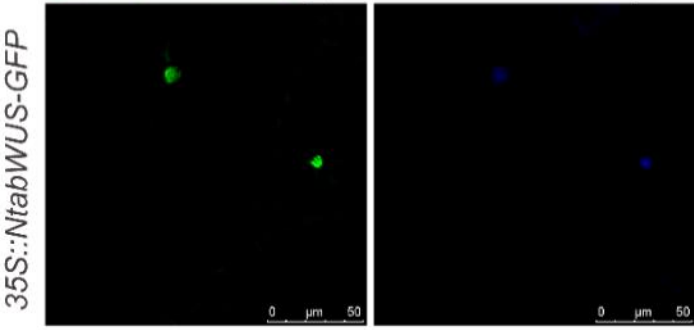

GAL4BD

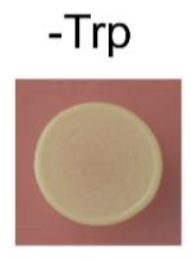

$\mathrm{X} /$-Trp

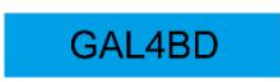

GAL4BD

NtabWUS
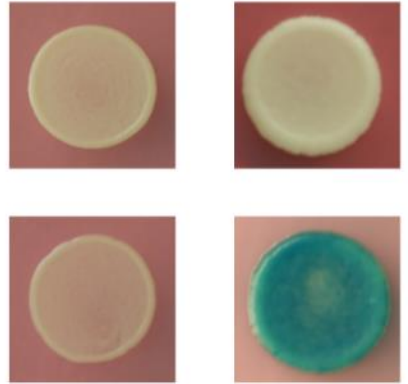

Figure 9. Subcellular localization and transactivation activity assay. (A) NtabWUS-GFP fusion constructs and green fluorescent protein (GFP) driven by the 35S promoter were transiently expressed in tobacco. DAPI (dye 4,6-diamidino-2-phenylindole) staining showed the nucleus. (B) NtabWUS was fused with the GAL4 (BD) DNA-binding domain in pBridge and transformed into yeast strain AH109. The transformed yeast cells were streaked on the SD/-Trp. BF, bright field; Trp, tryptophan.

\subsection{Genetic Complementation Analysis}

To further investigate potential functions of the identified WOX genes, we tested NtabWUS for its ability to rescue the Arabidopsis wus-1 mutant, which carries a loss-of-function point mutation in the gene AtWUS. Compared to wild-type, the wus-1 mutant had a clearly defective shoot meristem $[5,43]$ and failed to develop into a normal inflorescence (Figure 10A,D). Additionally, in contrast to the wild-type, wus-1 plants showed severe defects in floral organ development. The wild-type flowers contained six stamens and one central gynoecium (Figure 10B), while wus-1 flowers had only one central stamen present with no central gynoecium (Figure 10E). Besides, the GFP of the enhancer trap line J2341, which showed specific expression in the SAM [44] and in the distal meristem of wild-type roots [45], was absent in the wus-1 mutant (Figure 10C,F), confirming the disordered developmental process of the SAM in wus-1. 

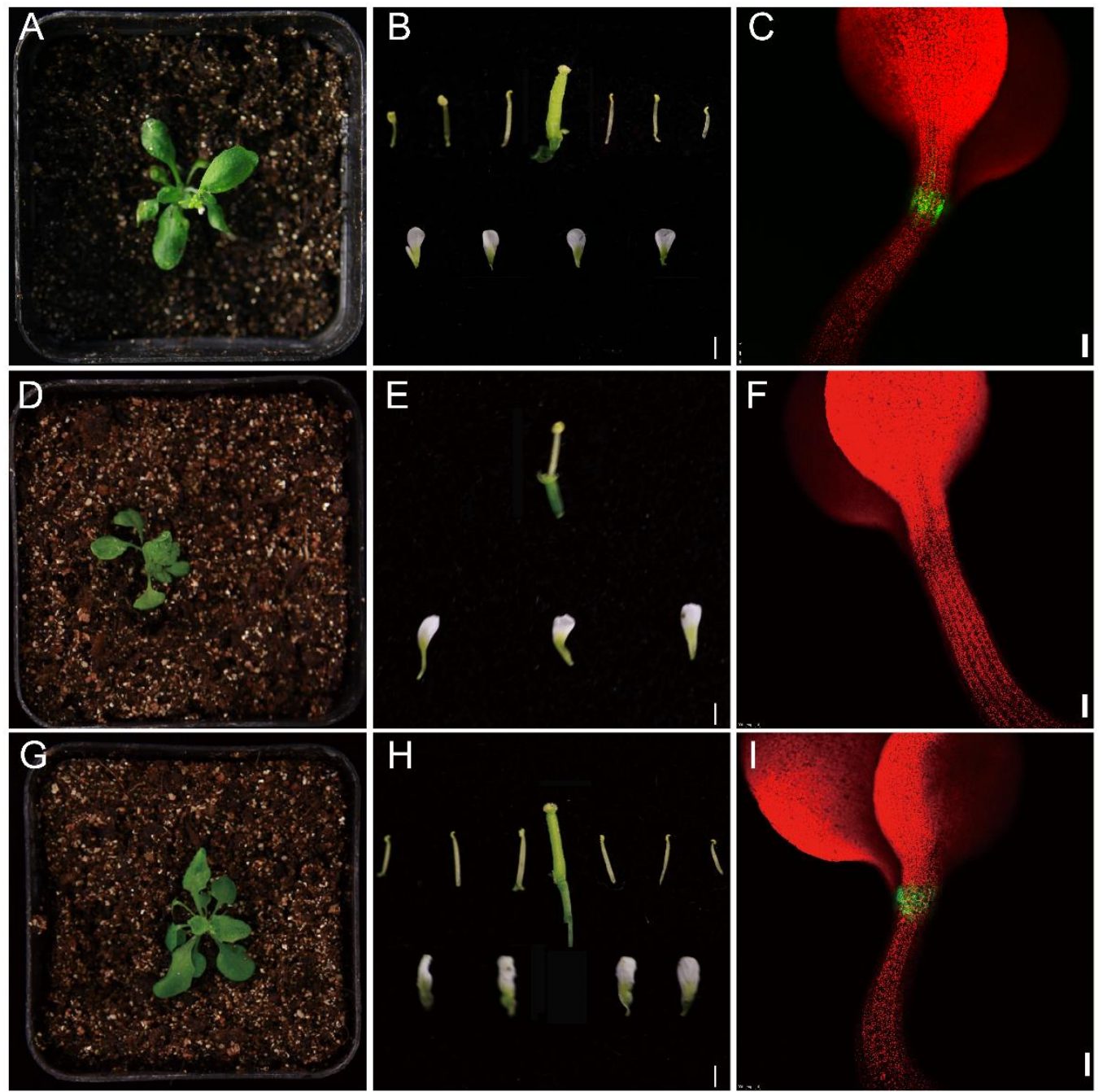

Figure 10. Analysis of NtabWUS function in maintenance of shoot apical stem-cell niche and floral development. Contrast to the wild-type (A,B), the wus-1 had defective shoot meristem and flower development (D,E). J2341, the GFP enhancer trap line, showed specific GFP expression in the shoot apical meristem (SAM) of wild-type Arabidopsis shoots (C), but not in the wus-1 mutant (F). (G-I) Interspecies rescue experiments with 4 lines with NtabWUS expressed in Arabidopsis wus-1 plants showed that NtabWUS can rescue the defects of wus-1 in Arabidopsis. Scale bars: $1 \mathrm{~mm}(\mathrm{~B}, \mathrm{E}, \mathrm{H})$ and $100 \mu \mathrm{m}(\mathrm{C}, \mathrm{F}, \mathrm{I})$.

In previous studies, genetic complementation experiments showed that the expression of AtWOX5 and AtWUS driven by the native WUS promoter rescued both premature termination of the SAM and the floral organ developmental defects in wus-1. While the expression of the WUS lineage AtWOX4 failed to rescue the wus-1 phenotypes. AtWOX9 and AtWOX13 were also unable to rescue the wus-1 SAM defects. These results indicate that the ability to maintain the Arabidopsis shoot stem-cell niche is not a common functional character of all the AtWOX family members [14].

NtabWUS contains the conserved homeodomain and the WUS/EAR motifs. When driven by the Arabidopsis AtWUS promoter, expression of NtabWUS was able to rescue the Arabidopsis wus-1 mutant phenotypes to wild-type. The AtWUS:NtabWUS plants had normal floral organs and J2341 signal (Figure 10G-I), implying that NtabWUS might also function in maintaining the shoot stem cell niche in tobacco. 


\section{Discussion}

Forty-five WOX genes from five Solanaceae species were identified and analyzed. Phylogenetic analysis with three different methods revealed similar topologies and these results were further supported by exon-intron organization analysis, motif analysis and expression analysis. The Solanaceae WOX members together with 15 Arabidopsis WOX proteins fell into three well-organized clades and were further divided into nine subgroups. Together with the results from expression analysis, peptide treatments, subcellular localization, transactivation activity, and complementation of known mutants, results from this study suggest that the WOX genes in the Solanaceae species are highly conserved in structure as well as functions in peptide signaling. Unique features in some of the WOX members are however also evident partially due to the extensive expansion of some subgroups through gene duplication as well as gene loss in some other subgroups after species divergence.

In the ancient clade, an expansion event was observed in the WOX13 subgroup in the three Nicotiana species. Four WOX13 subgroup members from the Nicotiana species, NtabWOX13c, NtabWOX13d, NsylWOX13b and NtomWOX13b were clustered together with StWOX13 and SIWOX13, members from potato and tomato respectively. The other four subgroup members from tobacco, NtabWOX13a, NtabWOX13b, NsylWOX13a and NtomWOX13a, however, were found to form a separate branch on the phylogenetic tree (Figure 2). The isolated group of WOX13 members were also found different in exon-intron organization and protein motifs. In comparison with the original members, these isolated members were found to have larger gene size with longer introns (Figure 3). Furthermore, the isolated members did not contain Motif 3 which was found to be present in all the other WOX13 subgroup members from the Solanaceae species (Figure 4). Within the same plant species distinct patterns of expression were observed between the original members and isolated members (Figure 6). The isolated members might be the result of gene duplication after the separation of the Nicotiana species from other Solanaceae plants.

The WOX9 and WOX11 subgroups that form the intermediate clade exhibited a highly conserved motif organization (Figure 4). The gene structures of these two subgroups, however, showed the highest variation compared with subgroups in the ancient clade and the modern clade, with exon numbers ranging from 3 to 5 within the genes of WOX9 subgroup and 2-4 within the WOX11 subgroup genes (Figure 3). Unlike WOX members of the other two clades, where genes in the same subgroup generally showed similar expression patterns, genes in the WOX9 and WOX11 subgroups were found to have distinct patterns of expression (Figure 6). All these suggested that the intermediate clade might be a rapidly evolving clade with its members showing large variations in gene structures, expression patterns and potential gene functions. In consistent with this hypothesis, distinct functions of WOX9 proteins from Arabidopsis and Petunia, and other Solanaceae species have been reported. The Petunia EVERGREEN/WOX9 has been shown to be essential for inflorescence development and architecture [46] while Arabidopsis WOX9/STIP together with WOX8/STPL is required for embryo patterning and vegetative SAM maintenance [22].

All WOX members of the modern clade contain a homeodomain and a WUS box except AtWOX7 in Arabidopsis. In comparison with its close homologue AtWOX5 and other members of the WOX5 subgroup, AtWOX7 lacks the second exon which harbors the WUS box (Figure 3, Figure 5). The WUS box has been shown to be the functional domain of AtWUS required for induction and maintenance of SAM cell identity. Although evolutionary closely related to AtWOX5 (Figure 2), lack of the critical WUS box may make the function of AtWOX7 different. Other than AtWOX7, which lacks homologue in the Solanaceae species, the motif organization and gene structures, as well as expression patterns of the modern clade members within the same subgroup were found to be similar.

In this study, significant difference was observed in expression patterns of WOX genes in different modern clade subgroups (Figure 6). Preferred expression of NtabWUS in shoot tips and NtWOX5 in root tips implies conserved functions of these two genes in the Nicotiana species. Differential expression changes of these genes in tested tissues upon CLE peptide treatments suggested the involvement of these WOX genes in peptide signaling that regulates various developmental processes (Figure 8). 
Particularly, the expression of NtabWUS could be suppressed by CLV3 peptide treatments, suggesting that CLV3 signaling also limits WUS expression in tobacco. In Arabidopsis, while CLV3 signaling limits expression of WUS, transcriptional factor WUS could promote the CLV3 transcription to form a feedback loop. NtabWUS subsequently was found to be localized in the nucleus and possessed transcriptional activation activity, suggesting that NtabWUS can activate CLV3 expression in tobacco and form a similar feedback loop. Further, genetic complementation analysis was carried out and it was found that expression of NtabWUS can rescue the Arabidopsis wus-1 mutant phenotypes. These results suggest that NtabWUS has conserved functions in the CLV3 peptide signaling pathway in maintaining shoot apical stem cell activity in tobacco.

Supplementary Materials: The following are available online at http:/ / www.mdpi.com/2073-4425/9/5/260/s1. Supplementary data associated with this article can be found in the online version. Supplementary Table S1. qRT-PCR primers used in this study. Supplementary Dataset S1. Protein sequences of the WOX gene family members in this study. Supplementary Dataset S2. The multiple sequence alignment of the full-length protein sequences of the WOX gene family members in this study using MAFFT. Supplementary Dataset S3. Schematic illustration of motifs in the WOX family members. The motif characterization was based on full-length proteins by MEME.

Author Contributions: X.L. and M.H. conducted the research and participated in the drafting of the manuscript. C.L., S.A., X.G. and C.G. assisted to the data analysis. Y.G. and Y.W. conceived the research, designed the experiments and drafted the manuscript. All authors read and approved the final manuscript.

Acknowledgments: We thank the current Guo lab members at the Tobacco Research Institute, Chinese Academy of Agricultural Sciences (CAAS) for discussion and critical reading of the manuscript. This work was supported by the National Natural Science Foundation of China (31571494), the Fundamental Research Funds for Central Non-profit Scientific Institution (Y2017JC27), and the Agricultural Science and Technology Innovation Program (ASTIP-TRIC02).

Conflicts of Interest: The authors declare no conflict of interest.

\section{References}

1. Van der Graaff, E.; Laux, T.; Rensing, S.A. The WUS homeobox-containing (WOX) protein family. Genome Biol. 2009, 10, 248. [CrossRef] [PubMed]

2. Dolzblasz, A.; Nardmann, J.; Clerici, E.; Causier, B.; van der Graaff, E.; Chen, J.; Davies, B.; Werr, W.; Laux, T. Stem cell regulation by Arabidopsis WOX genes. Mol. Plant 2016, 9, 1028-1039. [CrossRef] [PubMed]

3. Zhang, X.; Zong, J.; Liu, J.; Yin, J.; Zhang, D. Genome-wide analysis of WOX gene family in rice, sorghum, maize, Arabidopsis and poplar. J. Integr. Plant Biol. 2010, 52, 1016-1026. [CrossRef] [PubMed]

4. Murphy, E.; Smith, S.; De Smet, I. Small signaling peptides in Arabidopsis development: How cells communicate over a short distance. Plant Cell 2012, 24, 3198-3217. [CrossRef] [PubMed]

5. Mayer, K.F.; Schoof, H.; Haecker, A.; Lenhard, M.; Jürgens, G.; Laux, T. Role of WUSCHEL in regulating stem cell fate in the Arabidopsis shoot meristem. Cell 1998, 95, 805-815. [CrossRef]

6. Soyars, C.L.; James, S.R.; Nimchuk, Z.L. Ready, aim, shoot: Stem cell regulation of the shoot apical meristem. Curr. Opin. Plant Biol. 2016, 29, 163-168. [CrossRef] [PubMed]

7. Gao, X.; Guo, Y. CLE peptides in plants: Proteolytic processing, structure-activity relationship, and ligand-receptor interaction. J. Integr. Plant Biol. 2012, 54, 738-745. [CrossRef] [PubMed]

8. Yu, L.; Simon, E.J.; Trotochaud, A.E.; Clark, S.E. POLTERGEIST functions to regulate meristem development downstream of the CLAVATA loci. Development 2000, 127, 1661-1670. [PubMed]

9. Gagne, J.M.; Clark, S.E. The Arabidopsis stem cell factor POLTERGEIST is membrane localized and phospholipid stimulated. Plant Cell 2010, 22, 729-743. [CrossRef] [PubMed]

10. Schoof, H.; Lenhard, M.; Haecker, A.; Mayer, K.F.; Jürgens, G.; Laux, T. The stem cell population of Arabidopsis shoot meristems is maintained by a regulatory loop between the CLAVATA and WUSCHEL genes. Cell 2000, 100, 635-644. [CrossRef]

11. Stahl, Y.; Wink, R.H.; Ingram, G.C.; Simon, R. A signaling module controlling the stem cell niche in Arabidopsis root meristems. Curr. Biol. 2009, 19, 909-914. [CrossRef] [PubMed]

12. Katsir, L.; Davies, K.A.; Bergmann, D.C.; Laux, T. Peptide signaling in plant development. Curr. Biol. 2011, 21, 356-364. [CrossRef] [PubMed] 
13. Sparks, E.; Wachsman, G.; Benfey, P.N. Spatiotemporal signalling in plant development. Nat. Rev. Genet. 2013, 14, 631. [CrossRef] [PubMed]

14. Zhang, Y.; Jiao, Y.; Jiao, H.; Zhao, H.; Zhu, Y.-X. Two-step functional innovation of the stem-cell factors WUS/WOX5 during plant evolution. Mol. Biol. Evol. 2016, 34, 640-653. [CrossRef] [PubMed]

15. Kondo, Y.; Fukuda, H. The TDIF signaling network. Curr. Opin. Plant Biol. 2015, 28, 106-110. [CrossRef] [PubMed]

16. Breuninger, H.; Rikirsch, E.; Hermann, M.; Ueda, M.; Laux, T. Differential expression of genes mediates apical-basal axis formation in the Arabidopsis embryo. Dev. Cell 2008, 14, 867. [CrossRef] [PubMed]

17. Shimizu, R.; Ji, J.; Kelsey, E.; Ohtsu, K.; Schnable, P.S.; Scanlon, M.J. Tissue specificity and evolution of meristematic WOX3 function. Plant Physiol. 2009, 149, 841-850. [CrossRef] [PubMed]

18. Ichihashi, Y.; Tsukaya, H. Behavior of leaf meristems and their modification. Front. Plant Sci. 2015, 6, 1060. [CrossRef] [PubMed]

19. Park, S.O.; Zheng, Z.; Oppenheimer, D.G.; Hauser, B.A. The PRETTY FEW SEEDS2 gene encodes an Arabidopsis homeodomain protein that regulates ovule development. Development 2005, 132, 841-849. [CrossRef] [PubMed]

20. Kong, D.; Hao, Y.; Cui, H. The WUSCHEL related homeobox protein WOX7 regulates the sugar response of lateral root development in Arabidopsis thaliana. Mol. Plant 2016, 9, 261-270. [CrossRef] [PubMed]

21. Wu, X.; Chory, J.; Weigel, D. Combinations of WOX activities regulate tissue proliferation during Arabidopsis embryonic development. Dev. Biol. 2007, 309, 306-316. [CrossRef] [PubMed]

22. Haecker, A.; Groß-Hardt, R.; Geiges, B.; Sarkar, A.; Breuninger, H.; Herrmann, M.; Laux, T. Expression dynamics of WOX genes mark cell fate decisions during early embryonic patterning in Arabidopsis thaliana. Development 2004, 131, 657-668. [CrossRef] [PubMed]

23. Liu, J.; Sheng, L.; Xu, Y.; Li, J.; Yang, Z.; Huang, H.; Xu, L. WOX11 and 12 are involved in the first-step cell fate transition during de novo root organogenesis in Arabidopsis. Plant Cell 2014, 26, 1081-1093. [CrossRef] [PubMed]

24. Romera-Branchat, M.; Ripoll, J.J.; Yanofsky, M.F.; Pelaz, S. The WOX13 homeobox gene promotes replum formation in the Arabidopsis thaliana fruit. Plant J. 2013, 73, 37-49. [CrossRef] [PubMed]

25. Cao, Y.; Han, Y.; Meng, D.; Li, G.; Li, D.; Abdullah, M.; Jin, Q.; Lin, Y.; Cai, Y. Genome-wide analysis suggests the relaxed purifying selection affect the evolution of WOX genes in Pyrus bretschneideri, Prunus persica, Prunus mume, and Fragaria vesca. Front. Genet. 2017, 8, 78. [CrossRef] [PubMed]

26. Li, Y.; Zhu, Y.; Yao, J.; Zhang, S.; Wang, L.; Guo, C.; Nocker, S.; Wang, X. Genome-wide identification and expression analyses of the homeobox transcription factor family during ovule development in seedless and seeded grapes. Sci. Rep. 2017, 7, 12638. [CrossRef] [PubMed]

27. Tang, F.; Chen, N.; Zhao, M.; Wang, Y.; He, R.; Peng, X.; Shen, S. Identification and functional divergence analysis of WOX gene family in paper mulberry. Int. J. Mol. Sci. 2017, 18, 1782. [CrossRef] [PubMed]

28. Smitha Ninan, A.; Shah, A.; Song, J.; Jameson, P.E. Differential gene expression in the meristem and during early fruit growth of Pisum sativum L. identifies potential targets for breeding. Int. J. Mol. Sci. 2017, 18, 428. [CrossRef] [PubMed]

29. Segatto, A.L.; Turchetto-Zolet, A.C.; Aizza, L.C.; Monte-Bello, C.C.; Dornelas, M.C.; Margis, R.; Freitas, L.B. MAEWEST expression in flower development of two petunia species. Int. J. Mol. Sci. 2013, 14, 13796-13807. [CrossRef] [PubMed]

30. Chen, S.-K.; Kurdyukov, S.; Kereszt, A.; Wang, X.-D.; Gresshoff, P.; Rose, R. The association of homeobox gene expression with stem cell formation and morphogenesis in cultured Medicago truncatula. Planta 2009, 230, 827-840. [CrossRef] [PubMed]

31. Tadege, M.; Lin, H.; Bedair, M.; Berbel, A.; Wen, J.; Rojas, C.M.; Niu, L.; Tang, Y.; Sumner, L.; Ratet, P. STENOFOLIA regulates blade outgrowth and leaf vascular patterning in Medicago truncatula and Nicotiana sylvestris. Plant Cell 2011, 23, 2125-2142. [CrossRef] [PubMed]

32. Hu, B.; Jin, J.; Guo, A.-Y.; Zhang, H.; Luo, J.; Gao, G. GSDS 2.0: an upgraded gene feature visualization server. Bioinformatics 2015, 31, 1296-1297. [CrossRef] [PubMed]

33. Crooks, G.E.; Hon, G.; Chandonia, J.M.; Brenner, S.E. WebLogo: A sequence logo generator. Genome Res. 2004, 14, 1188-1190. [CrossRef] [PubMed]

34. R Core Team. R: A language and environment for statistical computing. R Foundation for Statistical Computing: Vienna, Austria. Available online: http:/ /www.R-project.org/ (accessed on 16 May 2018). 
35. Sheludko, Y.; Sindarovska, Y.; Gerasymenko, I.; Bannikova, M.; Kuchuk, N. Comparison of several Nicotiana species as hosts for high-scale Agrobacterium-mediated transient expression. Biotechnol. Bioeng. 2007, 96, 608-614. [CrossRef] [PubMed]

36. Gehring, W.; Müller, M.; Affolter, M.; Percival-Smith, A.; Billeter, M.; Qian, Y.; Otting, G.; Wüthrich, K. The structure of the homeodomain and its functional implications. Trends Genet. 1990, 6, 323-329. [CrossRef]

37. Lian, G.; Ding, Z.; Wang, Q.; Zhang, D.; Xu, J. Origins and evolution of WUSCHEL-related homeobox protein family in plant kingdom. Sci. World J. 2014, 534140. [CrossRef] [PubMed]

38. Kieffer, M.; Stern, Y.; Cook, H.; Clerici, E.; Maulbetsch, C.; Laux, T.; Davies, B. Analysis of the transcription factor WUSCHEL and its functional homologue in Antirrhinum reveals a potential mechanism for their roles in meristem maintenance. Plant Cell 2006, 18, 560-573. [CrossRef] [PubMed]

39. Ikeda, M.; Mitsuda, N.; Ohme-Takagi, M. Arabidopsis WUSCHEL is a bifunctional transcription factor that acts as a repressor in stem cell regulation and as an activator in floral patterning. Plant Cell 2009, 21, 3493-3505. [CrossRef] [PubMed]

40. Kalve, S.; De Vos, D.; Beemster, G.T. Leaf development: A cellular perspective. Front. Plant Sci. $2014,5,362$. [CrossRef] [PubMed]

41. Nakata, M.; Matsumoto, N.; Tsugeki, R.; Rikirsch, E.; Laux, T.; Okada, K. Roles of the middle domain-specific WUSCHEL-RELATED HOMEOBOX genes in early development of leaves in Arabidopsis. Plant Cell 2012, 24, 519-535. [CrossRef] [PubMed]

42. Zhao, Y.; Hu, Y.; Dai, M.; Huang, L.; Zhou, D.-X. The WUSCHEL-related homeobox gene WOX11 is required to activate shoot-borne crown root development in rice. Plant Cell 2009, 21, 736-748. [CrossRef] [PubMed]

43. Sarkar, A.K.; Luijten, M.; Miyashima, S.; Lenhard, M.; Hashimoto, T.; Nakajima, K.; Scheres, B.; Heidstra, R.; Laux, T. Conserved factors regulate signalling in Arabidopsis thaliana shoot and root stem cell organizers. Nature 2007, 446, 811. [CrossRef] [PubMed]

44. Kim, I.; Cho, E.; Crawford, K.; Hempel, F.D.; Zambryski, P.C. Cell-to-cell movement of GFP during embryogenesis and early seedling development in Arabidopsis. Proc. Natl. Acad. Sci. USA 2005, 102, 2227-2231. [CrossRef] [PubMed]

45. Ding, Z.; Friml, J. Auxin regulates distal stem cell differentiation in Arabidopsis roots. Proc. Natl. Acad. Sci. USA 2010, 107, 12046-12051. [CrossRef] [PubMed]

46. Rebocho, A.B.; Bliek, M.; Kusters, E.; Castel, R.; Procissi, A.; Roobeek, I.; Souer, E.; Koes, R. Role of EVERGREEN in the development of the cymose petunia inflorescence. Dev. Cell 2008, 15, 437-447. [CrossRef] [PubMed] 